\title{
Intracellular lipophilic inclusions of mycobacteria in vitro and in sputum
}

\author{
Natalie J. Garton, ${ }^{1,2}+$ Henriette Christensen, ${ }^{1,2}$ David E. Minnikin, ${ }^{2} \neq$ \\ Richard A. Adegbola ${ }^{3}$ and Michael R. Barer ${ }^{1} \dagger$
}

Author for correspondence: Natalie J. Garton. Tel: +44 116252 2955. Fax: +44 1162525030. e-mail:njg17@le.ac.uk

1,2 Department of
Microbiology and
Immunology ${ }^{1}$ and
Department of
Chemistry ${ }^{2}$
University of Newcastle,
Newcastle upon Tyne, UK
3 MRC Laboratories, Fajara,
Banjul, The Gambia,
West Africa

\section{INTRODUCTION}

In a study of the interactions between fluorescent lipid probes and mycobacteria, we observed that a substantial proportion of the cells contained intracellular lipophilic

\footnotetext{
† Present address: Microbiology and Immunology Department, Leicester University, PO Box 138, Medical Sciences Building, University Road, Leicester LE1 9HN, UK.

¥Present address: School of Biosciences, The University of Birmingham, Edgbaston, Birmingham B15 2TT, UK.

Abbreviations: DAG, diacylglycerol; FAME, fatty acid methyl ester; ILI, intracellular lipophilic inclusion; MB, Middlebrook 7H9 broth with $A D C$ enrichment; $\mathrm{PHB}$, poly- $\beta$-hydroxybutyrate; TAG, triacylglycerol; $\mathrm{YB}$, Youmans' broth.
}

\begin{abstract}
Although most mycobacterial lipids are thought to be associated with the cell envelope, the authors previously observed substantial deposits of intracellular lipophilic material. A Nile-red-based cytological assay was used to determine factors which affect the presence and natural history of intracellular lipophilic inclusions (ILIs) in Mycobacterium smegmatis. Development of ILls was associated with stationary-phase cultures in broth and with aged (6 days) colonies on agar. Using variants of Youmans' defined medium, the frequency and size of ILls was observed to be minimal in carbon-poor medium. ILIs were observed to form within $\mathbf{1 5}$ min after provision of fatty acids to the medium and after a period of several days in nitrogen-poor medium. Analysis of the non-polar lipid extracts of ILI-rich and -poor preparations indicated that the triacylglycerols (TAGs) were a major component of the inclusions. The acyl substituents of the TAGs varied according to whether they were formed in Middlebrook 7H9 broth, in low-nitrogen Youmans' broth or rapidly after oleic supplementation of Youmans' broth. These studies support a storage for TAGs in mycobacteria in addition to their previously suggested nce as components of the cell envelope. To assess a possible role for ILIs was applied to heavily positive sputum samples from patients with tuberculosis. Strong intracellular Nile red signals were obtained from acid-fast cells, indicating that ILI occur in M. tuberculosis in vivo. This may reflect a distinct physiological state of these cells, which it has not been possible to reproduce in vitro. These findings indicate that the uptake of long-chain fatty acids and TAG biosynthetic and degradative pathways are important aspects of mycobacterial lipid metabolism, meriting further investigation.
\end{abstract}

Keywords: mycobacterial lipids, triacylglycerols, storage lipids, nitrogen and carbon limitation, cytochemistry inclusions (ILIs) (Christensen et al., 1999). ILIs were demonstrated across a range of species and preliminary studies indicated that their occurrence was affected by growth conditions and the age of the culture.

Mycobacterial intracellular inclusion bodies were reported by Burdon (1946) and have subsequently been observed by others using both light and electron microscopy (Table 1). There has been little recent interest in these structures. Most studies have concentrated on ultrastructural issues, particularly on whether the inclusions are membrane-bound, and little is known about their natural history.

The chemical composition of the ILIs is unknown. 
Table 1. Summary of studies demonstrating inclusions within mycobacterial cells

\begin{tabular}{|c|c|c|c|}
\hline Organism & Method* & Comments & Reference \\
\hline M. tuberculosis & LM-Sudan black B & Demonstration of inclusion bodies & Burdon (1946) \\
\hline M. avium & EM-TS & $\begin{array}{l}\text { Electron-transparent vacuoles surrounded by thin dense } \\
\text { membrane }\end{array}$ & Knaysi et al. (1950) \\
\hline $\begin{array}{l}\text { M. leprae and } \\
\text { unknown } \\
\text { Mycobacterium }\end{array}$ & EM-TS & $\begin{array}{l}\text { Electron-transparent vacuoles surrounded by dense outer } \\
\text { ring }\end{array}$ & Brieger \& Glauert (1956) \\
\hline M. kansasii & EM-TS & $\begin{array}{l}\text { Lipid droplets observed in bacteria grown in presence of } \\
\text { Tween } 80 \text {; not bound by unit membrane }\end{array}$ & Schaefer \& Lewis (1965) \\
\hline M. smegmatis & $\begin{array}{l}\text { LM-Oil red O; } \\
\text { EM-TS }\end{array}$ & Inclusions limited by a single-layered membrane & Gale \& McLain (1963) \\
\hline M. lepraemurium & EM-TS, NS & $\begin{array}{l}\text { No limiting membrane observed around large low-density } \\
\text { bodies }\end{array}$ & Whitehouse et al. (1971) \\
\hline M. smegmatis & EM-TS & $\begin{array}{l}\text { Droplets observed in cells that had been incubated in } \\
\text { presence of oleic acid }\end{array}$ & Weir et al. (1972) \\
\hline $\begin{array}{l}\text { M. aurum, } \\
\text { M. tuberculosis, } \\
\text { M. smegmatis }\end{array}$ & EM-TS & Inclusions enclosed by membrane & Barksdale \& Kim (1977) \\
\hline M. leprae & EM-TS & $\begin{array}{l}\text { Lipid vacuoles, some apparently surrounded by 'unit- } \\
\text { membrane'; droplets without membranes also observed }\end{array}$ & Draper (1982) \\
\hline M. paratuberculosis & EM-TS & $\begin{array}{l}\text { Low-density vacuoles observed in cells that had been } \\
\text { incubated in presence of Tween } 80 \text {; number increased } \\
\text { with increasing Tween concentration; none present in } \\
\text { cells incubated without Tween }\end{array}$ & Van Boxtel et al. (1990) \\
\hline
\end{tabular}

*LM, light microscopy; EM, electron microscopy; TS, thin section; NS, negative staining.

However, since the ability to accumulate storage lipids has been recognized in several micro-organisms we took this as our starting point. The principal candidate compounds are poly- $\beta$-hydroxybutyrate (PHB), triacylglycerols (TAGs) and wax esters (Koval'chuk, 1973; Thiele, 1972; Dawes \& Senior, 1973; Ratledge, 1984). With the exception of a study on Mycobacterium album grown on hexadecane vapours (Scott \& Finnerty, 1976), mycobacteria have not previously been reported to contain PHB. However, M. album has subsequently been reclassified as Tsukamurella (Goodfellow et al., 1991). Mycobacteria are known to produce high levels of acylglycerols (Minnikin, 1982), which have generally been attributed to the cell envelope (Daffé \& Draper, 1998). The uptake of radiolabelled fatty acids has led to the subsequent observation of radioactive TAGs (McCarthy, 1971; Weir et al., 1972).

Here we report our studies on ILIs in Mycobacterium smegmatis and preliminary work on these structures in Mycobacterium tuberculosis. We have investigated the factors affecting the occurrence of ILIs, whether they may be formed by direct fatty acid uptake or biosynthetically using de novo synthesized fatty acids, and also the corresponding ILI lipid composition. We also present evidence that ILIs are present in M. tuberculosis cells in human sputum. We suggest that our results have important implications for the understanding of lipid physiology in mycobacteria, and that they are relevant to the metabolism of pathogenic mycobacteria in vivo and consequently present a potential target for treatment of mycobacterial diseases.

\section{METHODS}

Bacterial strains. Mycobacterium smegmatis $\mathrm{mc}^{2} 155$ was used. Routine culture was on Youmans' agar (Youmans' broth containing $2 \%, \mathrm{w} / \mathrm{v}$, agar: Subrahmanyam, 1964).

Labelling of cells, recording and presentation of images. Labelling of cultures with Nile red, microscopy and deconvolution of fluorescence images were performed as detailed by Christensen et al. (1999).

Comparison of growth on Middlebrook 7H10 and Youmans' agar. Colonial growth of $M$. smegmatis on Middlebrook 7H10 with OADC enrichment (MA, Becton Dickinson) or Youmans' agar (YA) was removed daily and labelled.

Comparison of growth on Middlebrook 7H9 and Youmans' broth. Fifty-millilitre volumes of Middlebrook 7H9 with ADC enrichment $(\mathrm{MB})$ or Youmans' broth $(\mathrm{YB})$ were inoculated at $4 \%$ with a suspension (approx. $10^{8}$ cells $\mathrm{ml}^{-1}$ ) of M. smegmatis from a freshly grown lawn (2 days). The cultures were incubated at $37^{\circ} \mathrm{C}$ with shaking (140 r.p.m.), and samples were removed as required and labelled with Nile red.

Growth of $\boldsymbol{M}$. smegmatis in variants of Youmans' medium. For a comparison of glycerol and glucose as major carbon sources, cultures were made as described for $\mathrm{YB}(4 \%, \mathrm{w} / \mathrm{v}$, glycerol) with $4 \%(\mathrm{w} / \mathrm{v})$ glucose substituted for glycerol. Duplicate samples were removed daily and labelled with Nile red. To supplement the medium with fatty acid, the method of 
preparation was adapted from Weir et al. (1972). Oleic acid $\left(\mathrm{C}_{18: 1}, 200 \mu \mathrm{l}\right)$ or palmitic acid $\left(\mathrm{C}_{16: 0}, 198 \mathrm{mg}\right)$ was added to $100 \mathrm{ml} \mathrm{BSA}$ solution (fraction $\mathrm{V}, 5 \%, \mathrm{w} / \mathrm{v}$ ). The mixture was emulsified by sonicating in a sonic bath (Decon FS 100b, mean power output $100 \mathrm{~W}$ ) for $3 \times 20 \mathrm{~min}$. The emulsion was then filter-sterilized and stored at $4{ }^{\circ} \mathrm{C}$ until required. Cultures were prepared in $45 \mathrm{ml} \mathrm{YB}$ as described and after $23 \mathrm{~h}$, fatty acid-BSA supplement $(5 \mathrm{ml})$ was added. Incubation was resumed and duplicate samples were removed and labelled as required. Cultures were also prepared as for $\mathrm{YB}$, in lowcarbon YB and low-nitrogen YB. The former contained $0.4 \%$ $(\mathrm{w} / \mathrm{v})$ glycerol while the latter contained $1.25 \mathrm{~g} \mathrm{~L}$-asparagine $1^{-1}$. Duplicate samples were removed daily and labelled with Nile red.

Preparation of samples of $\boldsymbol{M}$. smegmatis for lipid extraction. Two M. smegmatis cultures $(200 \mathrm{ml})$ were prepared in $\mathrm{MB}$ and were incubated for $27 \mathrm{~h}$. The cultures were harvested and cells washed with Youmans' broth containing no glycerol and with ammonium chloride $\left(2 \mathrm{~g} \mathrm{l}^{-1}\right)$ in place of $\mathrm{L}$-asparagine (no-carbon YB, $2 \times 20 \mathrm{ml}$ ). The cell pellet from one culture was stored at $-20^{\circ} \mathrm{C}$ prior to lipid analysis. The other cell pellet was resuspended in no-carbon $\mathrm{YB}(2 \times 10 \mathrm{ml})$ and used to inoculate two $1 \mathrm{l}$ flasks containing no-carbon YB $(190 \mathrm{ml})$. After 7 days incubation, the cultures were harvested and washed with PBS $(2 \times 20 \mathrm{ml})$. The cell pellet from one culture was stored at $-20{ }^{\circ} \mathrm{C}$ prior to lipid analysis. The other cell pellet was resuspended in YB $(2 \times 10 \mathrm{ml})$ and used to inoculate a $500 \mathrm{ml}$ flask containing $\mathrm{YB}$ with oleic acid supplement $(90 \mathrm{ml})$ and a $500 \mathrm{ml}$ flask containing low-nitrogen YB $(90 \mathrm{ml})$. The oleic acid YB culture was incubated for $1 \mathrm{~h}$ then harvested, washed and stored as described previously. The low-nitrogen YB culture was incubated with shaking for 9 days then harvested, washed and stored as described previously. Samples from each culture were labelled with Nile red prior to storage at $-20^{\circ} \mathrm{C}$.

Lipid extraction of $\boldsymbol{M}$. smegmatis. Samples of $M$. smegmatis grown under various conditions were lyophilized prior to extraction. The non-covalently bound non-polar lipids of the samples were extracted and analysed by TLC according to the methods of Dobson et al. (1985).

Purification of TAG components. The tentatively identified TAG components of each non-polar extract $(60 \mathrm{mg})$ from the samples of $M$. smegmatis and a sample of triolein $(60 \mathrm{mg})$ were purified by preparative TLC using plastic TLC plates (Merck, silica gel 60, $\mathrm{F}_{254}$, layer thickness $0.2 \mathrm{~mm}$ ). Plates were developed with petroleum ether (b.p. $40-60^{\circ} \mathrm{C}$ )/acetone $(95: 5, \mathrm{v} / \mathrm{v})$ and ' $T A G$ ' was visualized under UV after treating the plate with rhodamine $6 \mathrm{G}(0.001 \%, \mathrm{w} / \mathrm{v}$, in acetone $)$. The 'TAG' was removed from the plates and extracted into diethyl ether $(3 \times 10 \mathrm{ml})$ which after evaporation under nitrogen left approximately $7 \mathrm{mg}$ of purified 'TAG'. The purified 'TAG' and triolein ( $2 \mathrm{mg}$ ) were analysed by proton NMR (Brucker WP 200 spectrometer) and GC-MS.

GC-MS. The purified triolein and TAG samples from $M$. smegmatis were analysed by GC-MS on a Fisons 8060 GC, linked to a VG/Fisons Trio 1000 quadrupole mass spectrometer (electron voltage $70 \mathrm{eV}$, filament current $4.2 \mathrm{~A}$, source current $75 \mu \mathrm{A}$, source temperature $270{ }^{\circ} \mathrm{C}$, multiplier voltage, $500 \mathrm{~V}$, interface temperature $350^{\circ} \mathrm{C}$ ). The full scan mode acquisition (50-950 a.m.u. $\mathrm{s}^{-1}$ ) was controlled by an Intel 486 computer running VG Masslab software. The sample $(1 \mu \mathrm{l})$ in dichloromethane was injected using the cold column injection method. After the solvent peak had passed through the mass spectrometer $(5 \mathrm{~min})$ the GC temperature programme and data acquisition commenced. Separation was performed on a J\&W fused silica capillary column $(15 \mathrm{~m} \times 0.25 \mathrm{~mm}$ i.d.) coated $(0 \cdot 10 \mu \mathrm{m})$ with DB5-HT phase, with helium as the carrier gas (flow $1 \mathrm{ml} \mathrm{min}^{-1}$, pressure 30 $\mathrm{kPa}$ ). The temperature programme of the $\mathrm{GC}$ ran from 50 to $200{ }^{\circ} \mathrm{C}$ at $10^{\circ} \mathrm{C} \mathrm{m^{-1 }}$ and then from 200 to $370{ }^{\circ} \mathrm{C}$ at $5^{\circ} \mathrm{C} \mathrm{min}^{-1}$, and the final temperature was then held for $30 \mathrm{~min}$. The acquisition data were stored on DAT tape for later data processing, integration and printing.

GC analysis of fatty acid methyl esters. Fatty acid methyl esters (FAMEs) were prepared from purified 'TAG' (2 mg) according to the method of Walker et al. (1970). The FAMEs were analysed by GC performed on a PYE Unicam series 104 chromatograph equipped with a $6 \mathrm{ft} \times \frac{1}{4}$ inch o.d. (approx. $1.8 \mathrm{~m} \times 6 \mathrm{~mm}$ o.d.) stainless steel Silar 5CP column. FAMEs were chromatographed from $100^{\circ} \mathrm{C}$ to $240^{\circ} \mathrm{C}$ at $8^{\circ} \mathrm{C} \mathrm{min}{ }^{-1}$, with a carrier gas flow rate of $50 \mathrm{ml}$ nitrogen $\mathrm{min}^{-1}$. Authentic FAME standards were run for comparison. The FAMEs of the 'TAG' samples were identified by their relative retention times and by co-chromatography with the standard samples.

Combined Auramine-Nile red labelling of human sputum samples. Sputum samples from patients with clinical tuberculosis were spread evenly on the surface of glass slides, heat-fixed and labelled for $15 \mathrm{~min}$ in Auramine O/phenol (Sommers \& Good, 1985). The stain was differentiated in acid methanol for $15 \mathrm{~min}$, then the slides were washed briefly in tap water followed by labelling with Nile red $\left(10 \mu \mathrm{g} \mathrm{ml}^{-1}\right.$ in ethanol) for $10 \mathrm{~min}$. After further washing, the smear was treated with $\mathrm{KMnO}_{4}(0 \cdot 1 \% \mathrm{w} / \mathrm{v})$ for $1 \mathrm{~min}$, washed and mounted in PBS. Preparations were observed by fluorescence microscopy using a Leica DMLB microscope equipped with $50 \mathrm{~W} \mathrm{Hg}$ epifluorescence illumination. Images were captured using an integrating chip CCD Sony camera controlled by microcomputer (Optivision, UK).

\section{RESULTS}

Initial studies (Christensen et al., 1999) divided ILIs into peripheral deposits showing apparent contiguity with annular (cell envelope) labelling and prominent inclusions for which no connection with envelope labelling could be seen.

\section{Factors affecting the occurrence of ILls}

Culture medium. We first observed ILIs in cultures of $M$. smegmatis growing on Middlebrook 7H10 agar (MA) (Christensen et al., 1999) and the descriptive terms used below are defined therein (see also Fig. 1). While the ILIs seen in cells from MA cultures matured from peripheral deposits to more substantial inclusions between days 2 and 6, on Youmans' agar (YA) small peripheral deposits were observed throughout. Similar observations were made on cells grown in the broth equivalents of these two media (MB and YB). In MB at $21 \mathrm{~h}$ (exponential phase) peripheral deposits were apparent; at $45 \mathrm{~h}$ (early stationary phase) there were prominent inclusions and at $141 \mathrm{~h}$ the cells had lost their prominent internal inclusions and showed peripheral deposits again. Growth in YB showed peripheral deposits throughout $(6$ days) growth.

Occurrence of ILIs in variants of Youmans' medium. The clearest distinctions between ILI-rich and -poor cell 

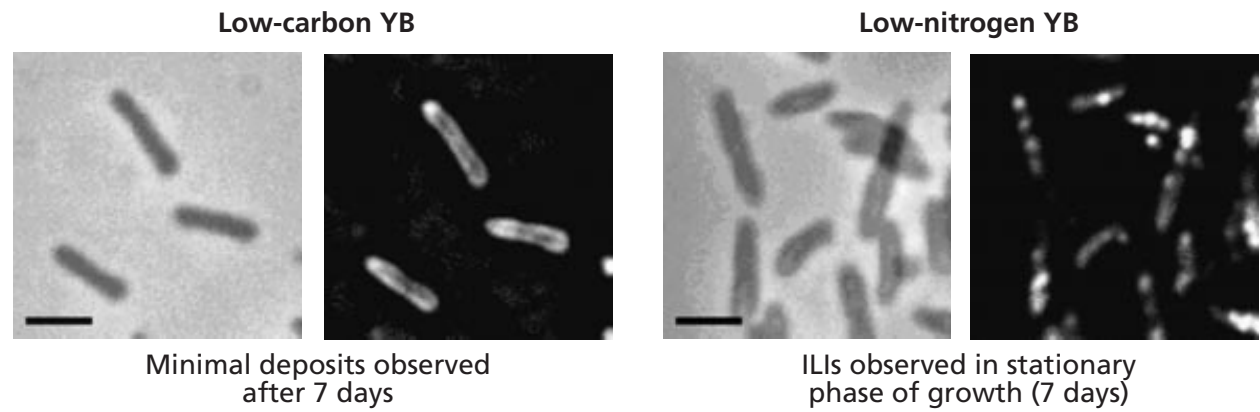

YB - glycerol as principal carbon source
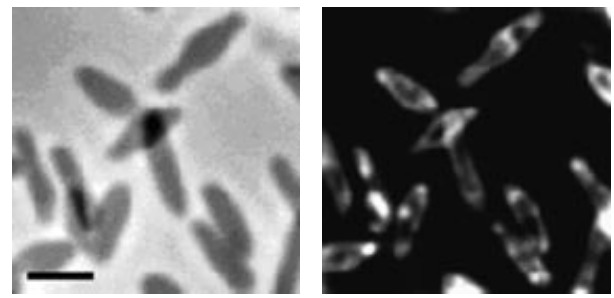

Peripheral deposits observed throughout growth (6 days)

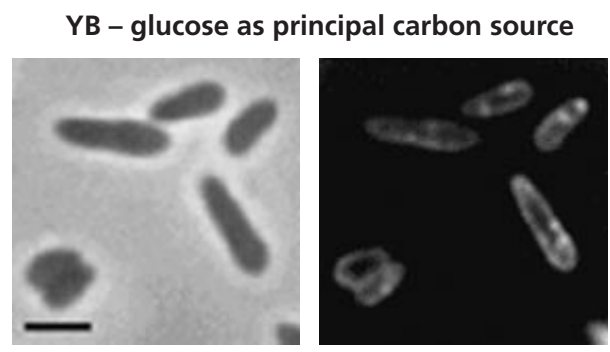

Peripheral deposits observed throughout growth (6 days)

YB $23 \mathrm{~h}$ then palmitic acid added
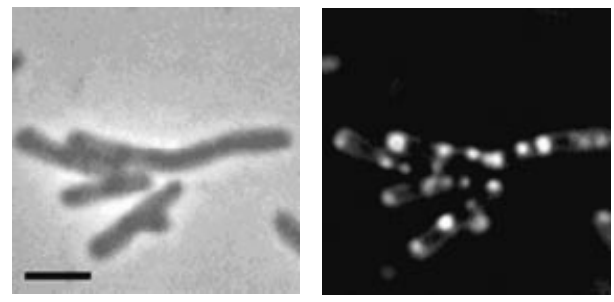

Prominent ILls observed after $1 \mathrm{~h}$

YB $23 \mathrm{~h}$ then oleic acid added

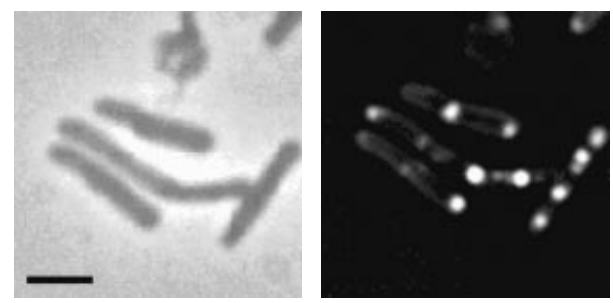

Prominent ILls observed after $1 \mathrm{~h}$

Fig. 1. Conditions found to influence the appearance of ILIs in cells of $M$. smegmatis. The distribution of Nile red under these conditions is shown with the phase image on the left and the deconvoluted fluorescence image on the right. Bars, $2 \mu \mathrm{m}$.

populations were obtained by manipulating growth conditions on Youmans' medium. The results of Nile red labelling of broth-grown cells are summarized in Fig. 1. After 7 days, low-carbon YB yielded a predominantly annular pattern of labelling and the minimum level of inclusions, while in low-nitrogen YB the annular labelling was lost and prominent inclusions were present. The use of glucose as an alternative principal carbon source to glycerol had no effect on the peripheral deposit pattern of labelling. Addition of exogenous fatty acid (oleic or palmitic) resulted in the formation of prominent inclusions within $1 \mathrm{~h}$. These cells had previously shown annular or small peripheral deposit labelling patterns. The more substantial inclusions were also observed by phase-contrast as bright refractile bodies as described by Christensen et al. (1999). These were observed in cells cultured on MA and in low-nitrogen YB. Apparently ILIs could be formed rapidly from uptake of fatty acids or from simple carbon sources in low-nitrogen conditions. The prominent ILIs observed in oleic-acid-supplemented cultures dis- appeared after a further $29 \mathrm{~h}$ incubation (data not shown).

\section{Chemical analysis of ILI-rich and -poor preparations}

The ability to accumulate storage lipids as ILIs has been recognized in several micro-organisms and candidate compounds are PHB or other poly- $\beta$-hydroxyalkanoates, TAGs and wax esters (Dawes \& Senior, 1973; Ratledge, 1984). As PHB is characteristically demonstrated as phase-bright ILIs we investigated this possibility first. M. smegmatis (20 mg lyophilized ILI-rich or -poor cells) did not contain detectable PHB by the assay method of Braunegg et al. (1978), which was reported to detect microgram quantities of PHB (satisfactory reference standard results were obtained). Harvested preparations of ILI-rich and -poor M. smegmatis were therefore subjected to the lipid analysis methods of Dobson et al. (1985). In order to obtain enough cell mass for analysis, cultures were grown in MB $(27 \mathrm{~h})$, transferred to no-carbon YB (7 days) and then transferred to 


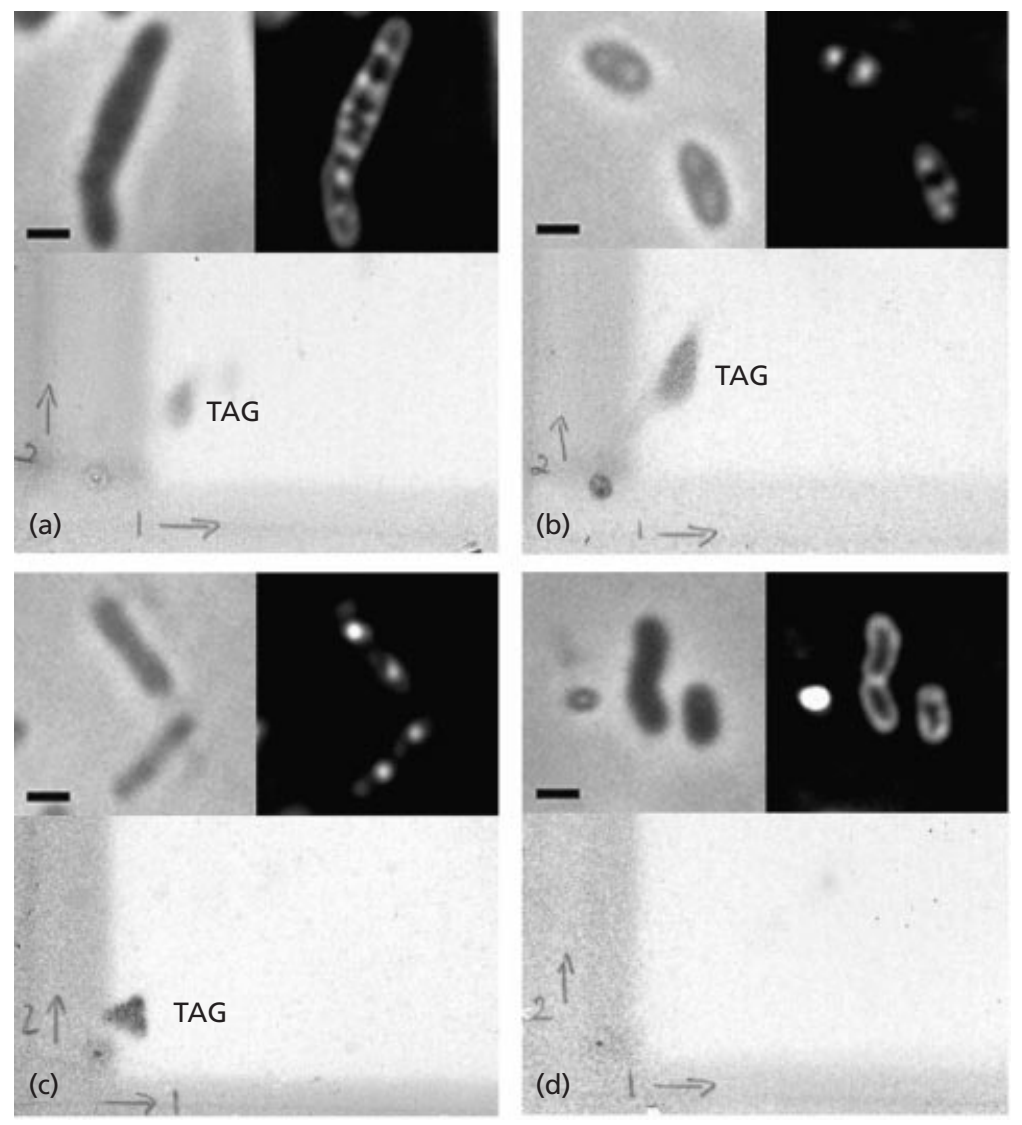

Fig. 2. Composite images showing thin-layer chromatograms of non-polar lipid and corresponding phase-contrast and deconvoluted fluorescence images of $M$. smegmatis cells conditioned in (a) MB (27 h), (b) low-nitrogen YB (6 days; transferred after 7 days in no-carbon YB), (c) oleic acid YB (15 min image; extract at $1 \mathrm{~h}$; transferred after 7 days in nocarbon YB), (d) no-carbon YB (6 days). Bars, $1 \mu \mathrm{m}$.

oleic acid YB (1 h) or low-nitrogen YB (7 days). Samples of cells from each culture condition were analysed. TLC analysis of non-polar lipid extracts showed clear evidence for a strong association between ILIs and the presence of a lipid component whose mobility was consistent with that of TAGs. The TLC analyses of the non-polar lipid extracts are presented together with images of cell preparations from which they were derived in Fig. 2. The putative TAG component was present in extracts derived from cultures grown in $\mathrm{MB}$, in low-nitrogen conditions and with an oleic acid supplement but was absent from the culture without a carbon source. It should be noted that the 'TAG' components of the M. smegmatis samples did not show identical TLC mobilities. This, in addition to the different staining intensities with molybdophosphoric acid, indicates that they may have had different component fatty acids.

The putative TAGs in the crude non-polar lipid extracts were purified by preparative TLC. Proton NMR and GC-MS analysis confirmed the identity of these extracts as TAGs (data not shown). The GC traces of each TAG extract showed multiple components, suggesting that mixtures of fatty acids were present. One such com- ponent from the oleic-acid-supplemented cells had a mass spectrum which corresponded to triolein.

\section{Fatty acid methyl ester (FAME) analyses of purified triacylglycerols}

The component FAMEs were differentiated by GC and are summarized in Fig. 3. The TAG substitution patterns were distinctive for each of the conditions analysed. While the MB and low-nitrogen YB results showed many similarities, oleic acid supplementation yielded a pattern dominated by oleate and the probable results of one and two rounds of $\beta$-oxidation $\left(\mathrm{C}_{16: 1} \Delta^{7}, \mathrm{C}_{14: 1} \Delta^{5}\right)$. Furthermore, fatty acids longer than $\mathrm{C}_{18}$ were absent from the oleic acid YB TAG profile. The chief difference between the MB and low-nitrogen YB patterns was that the ratios between saturated and unsaturated $\mathrm{C}_{18}$ components were in opposing directions, the unsaturated dominating thoughout the $\mathrm{MB}$ profile.

\section{Evidence for ILIs in M. tuberculosis}

Several attempts were made to demonstrate ILIs in $M$. tuberculosis cells grown in vitro. While strong, apparently internal, Nile red signals were obtained from 


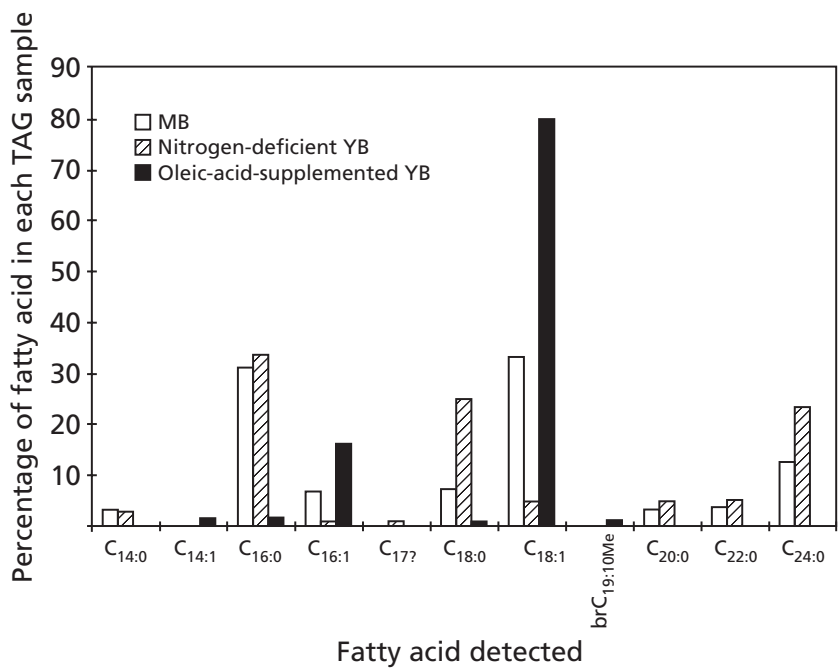

Fig. 3. Relative percentage abundance of fatty acids within each TAG fraction extracted from $M$. smegmatis grown in different media (see Fig. 1). Fatty acid abundance was determined by GC analysis of FAMEs and was calculated from peak integration. Fatty acid abbreviations are exemplified by $\mathrm{C}_{14: 0}$, tetradecanoate; $C_{16: 1}$, hexadecenoate; $\operatorname{brC}_{19: 10 \mathrm{Me}}, 10$ methyloctadecanoate (tuberculostearate).

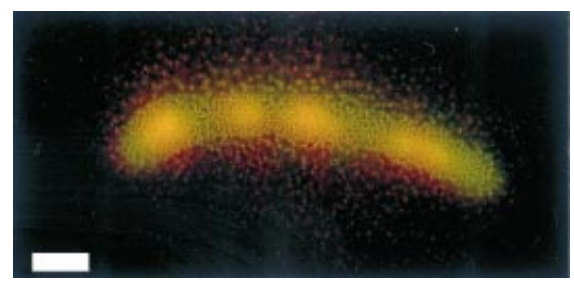

Fig. 4. Image of an acid-fast cell containing intracellular lipid inclusions in a sputum sample from a patient with clinical tuberculosis. The cell is dual-labelled with Auramine $\mathrm{O}$ and Nile red. Bar, $2 \mu \mathrm{m}$.

cells maintained in oleic-acid-supplemented YB (data not shown), the relatively small cell size compared to $M$. smegmatis made it impractical to confirm the structures as ILIs. However, whilst analysing images of $M$. tuberculosis cells in sputum samples obtained in The Gambia and on subsequent culture on LowensteinJensen medium it was noted that the cells in sputum were substantially larger (1.5-2-fold) than their subsequently isolated progeny. An attempt was therefore made to apply the Nile red labelling method to the cells in sputum samples. In order to confirm that Nile red labelling was present in mycobacterial cells as distinct from the other bacilli present it was necessary to develop a combined phenol/Auramine (acid-fast)-Nile red staining procedure; results from one patient's sample are shown in Fig. 4. The cell shows distinct ILIs and colocalized Auramine (green) and Nile red labelling is clearly demonstrated, confirming that the cells are mycobacteria. Similar ILIs were observed in sputum samples from four further patients.

\section{DISCUSSION}

M. smegmatis produced prominent ILIs when the cells were grown in rich medium $(\mathrm{MB})$, over a period of days under low-nitrogen conditions and rapidly (within 15 $\mathrm{min}$ ) in the presence of exogenous fatty acid. Prolonged incubation of the oleic acid YB culture led to apparent consumption of the prominent form of ILI. Under lowcarbon conditions cells showed no ILIs, although in some preparations, peripheral deposits remained. The presence of ILIs in cells was coincident with the observation of TAG in the non-polar lipid extract; no TAG was observed in cells conditioned in no-carbon YB. This circumstantial evidence implies that the ILIs represent the cellular location of storage lipid and that a major component is TAG. The location of mycobacterial TAG has not previously been demonstrated and is usually attributed to the cell envelope (Daffé \& Draper, 1998). It is possible that the ILIs may contain some free fatty acid, particularly when oleic acid has been added. Preliminary studies using an alternative TLC system indicate that free fatty acids are a minor component of non-polar lipid extract in comparable experiments, but this point requires further attention.

The fatty acid profiles of each TAG component reflected the conditions of culture: the oleic acid YB TAG showed direct incorporation of oleic acid, and the MB TAG and low-nitrogen YB TAG contained a range of de novosynthesized fatty acids. The metabolic pathways of TAG biosynthesis in mycobacteria remain to be elucidated. In yeast, phosphatidic acid is a common precursor for both membrane phospholipid and TAG biosynthesis (Pieringer, 1989). The biosynthetic pathway for the formation of mycobacterial TAG may also branch from phospholipid synthesis at this point, with dephosphorylation to form diacylglycerol (DAG) and acyl transfer to yield TAG.

Such a high proportion of $\mathrm{C}_{18: 1}$ in the oleic acid $\mathrm{YB}$ TAG was unexpected. If TAG was formed by acyl transfer to DAG derived from endogenous phosphatidic acid, $\mathrm{C}_{18: 1}$ would be expected to account for little more than one-third of the acyl substituents. The much greater proportion of $\mathrm{C}_{18: 1}$ may reflect de novo synthesis of dioleoyl phosphatidic acid with exogenous oleic acid, followed by further acylation to form triolein. We were surprised by the rapid accumulation of ILIs, which were observed $15 \mathrm{~min}$ after transfer of the cells to oleic acid YB (the corresponding TAGs were analysed after $1 \mathrm{~h}$ ). One explanation of the rapid accumulation of ILIs and TAG containing such a high proportion of $\mathrm{C}_{18: 1}$ is that TAGs may form to detoxify free fatty acid. This role of TAG accumulation was first suggested by McCarthy (1971) and was supported by Weir et al. (1972) in a study demonstrating the direct incorporation of $\left[{ }^{14} \mathrm{C}\right]$ oleic acid into TAG. We have observed that the rapid accumulation of ILIs in the presence of oleic acid is inhibited by azide (N. J.G., unpublished results). If the 
direct incorporation of host fatty acid into TAG prior to further catabolism is important in vivo, this step may represent a new chemotherapeutic target.

The absence of fatty acids longer than $\mathrm{C}_{18}$ in the oleic acid YB TAG presumably reflects the carbon-restricted state of the cells prior to $\mathrm{C}_{18: 1}$ uptake and confirms that TAG formed in the cells in $\mathrm{MB}$ is assimilated during subsequent incubation in no-carbon YB. $\beta$-Oxidation of $\mathrm{C}_{18: 1}$, forming $\mathrm{C}_{16: 1}$ and $\mathrm{C}_{14: 1}$, is a further consequence of the previous carbon restriction of the cells and will provide necessary energy and acetate units for the synthesis of required metabolites. $C_{16: 1} \Delta^{7}$ formed by the $\beta$-oxidation of $\mathrm{C}_{18: 1}$ and $\mathrm{C}_{16: 1} \Delta^{9}$ (a possible component of the fatty acid reservoir) formed by the action of $\Delta^{9}$ desaturase would not be distinguished using this GC method.

The MB TAG FAME profile contained an increased proportion of unsaturated fatty acids compared to the low-nitrogen YB TAG profile. This may reflect the different growth phase of the cells in these conditions. Phospholipids of $M$. smegmatis contain a greater proportion of $\mathrm{C}_{18: 1}$ and $\mathrm{C}_{16: 1}$ than the corresponding saturated fatty acids (Walker et al., 1970). The majority of the short-chain unsaturated fatty acids within the cell would be located in phospholipid, whereas saturated fatty acids as biosynthetic precursors of mycolates, or substituents of complex lipids, would be utilized in the outer layers of the cell envelope. Turnover of phospholipid during exponential growth $(\mathrm{MB}, 27 \mathrm{~h})$ might therefore enhance levels of $C_{18: 1}$ and $C_{16: 1}$ available for incorporation into intracellular TAG. There would be little or no turnover of lipids which require short-chain saturated fatty acid. The FAME profile of low-nitrogen YB TAG (after 7 days in low-nitrogen YB) indicates that the cells have recovered from the carbon restriction of no-carbon YB incubation and are again synthesizing a range of fatty acids $\left(\mathrm{C}_{14}-\mathrm{C}_{24}\right)$. As the amount of nitrogen available to the cells decreases, it is possible that there is reduced turnover of phospholipid and increased incorporation of de novo-synthesized saturated fatty acid into TAG as a result of a different growth state.

Few prokaryotes are known to utilize TAGs as energy reserves and their physiological role in mycobacteria has not been defined. Streptomyces spp. have been observed to accumulate TAG as ILIs in mycelia at the stationary phase of growth (Packter \& Olukoshi, 1995). It has been suggested that this TAG may act as a carbon source for the production of secondary metabolites, e.g. antibiotics (Olukoshi \& Packter, 1994). Studies on the environmental isolate Rhodococcus opacus strain PD630 have demonstrated the accumulation and mobilization of TAGs (which coincided with the presence of ILIs) under different growth conditions (Alvarez et al., 1996, 2000; Wältermann et al., 2000). The accumulation of TAGs has also been described for species of Actinomyces (Koval'chuk, 1973) and Acinetobacter (Scott \& Finnerty, 1976).

The striking demonstration of ILIs by combined acidfast and Nile red labelling of bacteria in human sputum provides strong circumstantial evidence that at least some processes observed in $M$. smegmatis are also a feature in the metabolism of M. tuberculosis in vivo. As we have been unable to produce large, ILI-containing cells of M. tuberculosis in vitro, we suggest that the cells observed in sputum may be in a physiological state distinct from that of cells produced in laboratory studies.

The degree to which TAG (ILI) formation, utilization and downstream processing of its components are essential to growth, viability and pathogenicity also remains to be investigated. The proposed storage role of ILIs and TAGs may be advantageous for mycobacteria in vivo. Preliminary studies have shown that $M$. tuberculosis $\mathrm{H}_{37} \mathrm{Rv}$ produces TAG when incubated in oleic-acid-supplemented YB (N. J.G., unpublished results). Much lipid would be available to M. tuberculosis within mammalian cells and it has been proposed that in vivo, the bacilli are lipolytic rather than lipogenic (Wheeler \& Ratledge, 1994). Fatty acid sequestered from the host may be stored as TAG and this, or de novo synthesized TAG, might be relevant to survival in a nonreplicating state.

\section{ACKNOWLEDGEMENTS}

This work was supported by the Wellcome Trust (GR 039680 and Prize Studentship awarded to N. J.G.). Technical support from staff at the MRC laboratories at Fajara is gratefully acknowledged. We also thank Professor K. P. W. J. McAdam and Dr T. Corrah for facilitating this work.

\section{REFERENCES}

Alvarez, H. M., Mayer, F., Fabritius, D. \& Steinbüchel, A. (1996). Formation of intracytoplasmic lipid inclusions by Rhodococcus opacus strain PD 630. Arch Microbiol 165, 377-386.

Alvarez, H. M., Kalscheur, R. \& Steinbüchel, A. (2000). Accumulation and mobilisation of storage lipids by Rhodococcus opacus PD630 and Rhodococcus ruber NCIMB 40126. Appl Microbiol Biotechnol 54, 218-223.

Barksdale, L. \& Kim, K.-S. (1977). Mycobacterium. Bacteriol Rev 41, 217-372.

Braunegg, G., Sonnleitner, B. \& Lafferty, R. M. (1978). A rapid gas chromatographic method for the determination of poly- $\beta$ hydroxybutyric acid in microbial biomass. Eur J Appl Microbiol 6, 29-37.

Brieger, E. M. \& Glauert, A. M. (1956). Electron microscopy of the leprosy bacillus: a study of submicroscopical structure. Tubercle 37, 195-206.

Burdon, K. L. (1946). Disparity in appearance of true Hansen's bacilli and cultured leprosy bacilli when stained for fat. J Bacteriol 57, 679-680.

Christensen, H., Garton, N. J., Horobin, R. W., Minnikin, D. E. \& Barer, M. R. (1999). Lipid domains of mycobacteria studied with fluorescent molecular probes. Mol Microbiol 31, 1561-1572.

Daffé, M. \& Draper, P. (1998). The envelope layers of mycobacteria with reference to their pathogenicity. Adv Microb Physiol 39, 131-203.

Dawes, E. A. \& Senior, P. J. (1973). The role and regulation of energy reserve polymers in microorganisms. Adv Microb Physiol 10, 135-266. 
Dobson, G., Minnikin, D. E., Minnikin, S. M., Parlett, J. H., Goodfellow, M., Ridell, M. \& Magnusson, M. (1985). Systematic analysis of complex mycobacterial lipids. In Chemical Methods in Bacterial Systematics (Society for Applied Bacteriology Technical Series no. 20), pp. 237-265. Edited by M. Goodfellow \& D. E. Minnikin. London: Academic Press.

Draper, P. (1982). The anatomy of the mycobacteria. In The Biology of the Mycobacteria, pp. 9-52. Edited by C. Ratledge \& J. Stanford. London: Academic Press.

Gale, G. R. \& McLain, H. H. (1963). Effect of ethambutol on cytology of Mycobacterium smegmatis. J Bacteriol 86, 749-756.

Goodfellow, M., Zakrzewska-Czerwinska, J., Thomas, E. G., Mordarski, M., Ward, A. C. \& James, A. L. (1991). Polyphasic taxonomic study of the genera Gordona and Tsukamurella including the description of Tsukamurella wratislavensis sp. nov. Zentbl Bakteriol 275, 162-178.

Knaysi, G., Hillier, J. \& Fabricant, C. (1950). The cytology of an avian strain of Mycobacterium tuberculosis studied with the electron and light microscopes. J Bacteriol 60, 423-447.

Koval'chuk, L. P., Donets, A. Y. \& Razumovskii, P. N. (1973). On the biosynthesis of lipids by actinomycetes when cultured on different media. Microbiology (English translation of Mikrobiologiya) 42, 567-571.

McCarthy, C. (1971). Utilization of palmitic acid by Mycobacterium avium. Infect Immun 4, 199-204.

Minnikin, D. E. (1982). Lipids: complex lipids, their chemistry, biosynthesis and roles. In The Biology of the Mycobacteria, pp. 95-185. Edited by C. Ratledge \& J. Stanford. London: Academic Press.

Olukoshi, E. R. \& Packter, N. M. (1994). Importance of stored triacylglycerols in Streptomyces: possible carbon source for antibiotics. Microbiology 140, 931-943.

Packter, N. M. \& Olukoshi, E. R. (1995). Ultrastructural studies of neutral lipid localisation in Streptomyces. Arch Microbiol 164, 420-427.

Pieringer, R. A. (1989). Biosynthesis of non-terpinoid lipids. In Microbial Lipids, vol. 2, pp. 51-114. Edited by S. G. Wilkinson \& C. Ratledge. London: Academic Press.

Ratledge, C. (1984). Microbial oils and fats - an overview. In Biotechnology for the Oils and Fats Industry, pp. 119-127. Edited by P. Dawson, C. Ratledge \& J. Rattray. Champaign, IL: American Oil Chemists' Society.
Schaefer, W. B. \& Lewis, C. W., Jr (1965). Effect of oleic acid on growth and cell structure of mycobacteria. J Bacteriol 90, 1438-1447.

Scott, C. C. L. \& Finnerty, W. R. (1976). A comparative analysis of the ultrastructure of hydrocarbon-oxidising micro-organisms. J Gen Microbiol 94, 342-350.

Sommers, H. M. \& Good, R. C. (1985). Mycobacterium. In Manual of Clinical Microbiology, 4th edn, pp. 216-248. Edited by E. H. Lennette, A. Balows, W. J. Hausler, Jr \& H. J. Shadomy. Washington, DC: American Society for Microbiology.

Subrahmanyam, D. (1964). Studies on the polyglycerolphosphatide of Mycobacterium tuberculosis. Can J Biochem 42, 1195-1201.

Thiele, O. W., Dreysel, J. \& Hermann, D. (1972). The free lipids of two different growth strains of hydrogen-oxidising bacteria in relation to their growth phases. Eur J Biochem 29, 224-236.

Van Boxtel, R. M., Lambrecht, R. S. \& Collins, M. T. (1990). Effect of polyoxyethylene sorbate compounds (Tweens) on colonial morphology, growth and ultrastructure of Mycobacterium paratuberculosis. APMIS 98, 901-908.

Walker, R. W., Barakat, H. \& Hung, J. G. C. (1970). The positional distribution of fatty acids in the phospholipids and triglycerides of Mycobacterium smegmatis and M. bovis BCG. Lipids 5, 684-691.

Wältermann, M., Luftmann, H., Baumeister, D., Kalscheuer, R. \& Steinbüchel, A. (2000). Rhodococcus opacus strain PD630 as a new source of high-value single-cell oil? Isolation and characterization of triacylglycerols and other storage lipids. Microbiology 146, 1143-1149.

Weir, M. P., Langridge, W. H. R., III \& Walker, R. W. (1972). Relationships between oleic acid uptake and lipid metabolism in Mycobacterium smegmatis. Am Rev Respir Dis 106, 450-457.

Wheeler, P. R. \& Ratledge, C. (1994). Metabolism of Mycobacterium tuberculosis. In Tuberculosis: Pathogenesis, Protection and Control, pp. 353-385. Edited by B. R. Bloom. Washington, DC: American Society for Microbiology.

Whitehouse, R. L. S., Ching Wong, P. \& Jackson, F. L. (1971). Ultrastructure of Mycobacterium lepraemurium. Int J Lepr 39, 151-163.

Received 21 March 2002; revised 13 May 2002; accepted 31 May 2002. 